\title{
Chronic toxicological study of the stem bark aqueous extract from Libidibia ferrea
} Mart. ex Tul.

Estudo toxicológico crônico do extrato aquoso da casca do caule de Libidibia ferrea Mart. ex Tul.

\section{Carlos Fernando Brasileiro de Vasconcelos ${ }^{1}$, Hélida Maria de Lima Maranhão ${ }^{1}$, João Henrique da Costa- Silva ${ }^{2}$, Cristiano Ribeiro de Lima ${ }^{1}$, Jacinto da Costa Silva Neto ${ }^{3}$, Sérgio Faloni de Andrade ${ }^{4}$, Fabiano Ferreira ${ }^{5}$, Almir Gonçalves Wanderley ${ }^{1,5^{* *}}$}

'Programa de Pós-Graduação em Ciências Farmacêuticas, Centro de Ciências da Saúde, Universidade Federal de Pernambuco, Recife, 50740-521, Brazil; '²Departamento de Educação Física e Ciências do Esporte, Universidade Federal de Pernambuco, Vitória de Santo Antão, 55608-250, Brazil; ${ }^{3}$ Departamento de Histologia e Embriologia, Universidade Federal de Pernambuco, Recife, 50670-901, Brazil; ${ }^{4}$ Centro de Pesquisa para Biociências e Tecnologia de Saúde (CBIOS), Universidade Lusófona, 1749-024, Lisbon, Portugual; ${ }^{5}$ Departamento de Fisiologia e Farmacologia, Universidade Federal de Pernambuco, Recife, 50760-901, Brazil.

corresponding author: almir.wanderley@ufpe.br

\begin{abstract}
Libidibia ferrea Martius Ext Tul. has been used in popular medicine to treat a wide range of diseases such as diabetes, gastric ulcer, and cancer; however, no preclinical safety study of the stem bark aqueous extract has been identified. We studied the chronic toxicity of an aqueous extract of $L$. ferrea stem bark in mice with oral doses of 300 and $1500 \mathrm{mg} /$ $\mathrm{kg} /$ day for 12 weeks. As indicators of toxicity, body weight, as well as food and water intake, were evaluated. Analysis of biochemical and haematological parameters and histopathologic studies were also conducted. The groups treated with $L$. ferrea presented significant loss in body weight gain and an irregular pattern of consumption of water and feed. There was also a marked increase in the white blood cell count and an important reduction in the levels of aspartate aminotransferase, amylase, and lactate dehydrogenase. Histopathological analysis revealed the presence of inflammation in the small intestine and kidneys. The data set indicates that repeated administration of the aqueous extract of Libidibia ferrea stem bark is not completely safe in Swiss mice as evidenced by impairment of mice growth, development of nephro-enterotoxicity, which consequently leads to alteration of some biochemical, and hematological parameters.
\end{abstract}

Keywords: Libidibia ferrea Martius Ext Tul., chronic toxicity, biochemical parameters, hematological parameters

\begin{abstract}
Resumo
Libidibia ferrea Martius Ext Tul. tem sido usada na medicina popular para tratar uma ampla variedade de doenças como diabetes, úlcera gástrica, câncer, no entanto, poucos estudos, de segurança pré-clínica foram identificados com o extrato aquoso da casca do caule. Assim, estudámos a toxicidade crônica desse extrato aquoso em camundongos Swiss, tratados com veículo (água) ou extrato aquoso (300 e $1500 \mathrm{mg} / \mathrm{kg}$ pc/dia) por via oral durante 12 semanas. Como indicadores de toxicidade foram avaliados massa corporal, assim como, a ingestão de alimentos e água, para além de parâmetros bioquímicos, hematológicos e histopatológicos. Não observámos mortalidade ou alterações toxicológicas clinicamente significativas durante o período experimental. Contudo, os grupos tratados com $L$. ferrea apresentaram perda significativa no ganho de massa corporal e padrão de consumo irregular de água e ração, a par de acentuada leucocitose e redução nos níveis de aspartato aminotransferase, lactato desidrogenase e amilase. A histopatologia revelou inflamação no intestino delgado e rins. Os resultados indicam que a administração em doses repetidas do extrato aquoso da casca do caule de Libidibia ferrea não é completamente seguro em camundongos Suíços. Como evidenciado pelo comprometimento do ganho de massa corporal dos animais, desenvolvimento de nefro-enterotoxicidade.
\end{abstract}

Palavras-chave: Libidibia ferrea Martius Ext Tul., toxicidade crônica, parâmetros bioquímicos, parâmetros hematológicos. 


\section{Introduction}

Brazil has a rich fauna and flora distributed in the Amazon, Cerrado, Caatinga, Atlantic Forest, Pantanal, and Pampa biomes. In order to exploit this richness of biodiversity in a sustainable manner, in 2006 the Brazilian government created the National Policy on Medicinal Plants and Herbal Medicines, whose pillars are to guarantee the Brazilian population safe access and the rational use of medicinal and herbal medicines safely, effectively and with good quality within the Unified Health System, developing the production chain and the national industry through exchanges between academia and private initiatives (1).

Preferably native species that have robust evidence of efficacy are systematically listed to compose the National List of Medicinal Plants of Interest to the Unified Health System in the concept of expanding research aimed at the production chain in herbal medicines and primary health care (2).

Among these species is Libidibia ferrea var. parvifolia (Mart. ex Tul.) L.P. Queiroz (Leguminosae), whose basionym is Caesalpinia ferrea (3) and which is popularly known as "pau-ferro" or "jucá". This species is considered endemic in the North and Northeast regions of Brazil. In folk medicine, various parts (fruits, leaves, seeds, and stem bark) of L. ferrea are used to treat multiple diseases, a sui generis characteristic that attests to its potential as a candidate for herbal medicine. In fact, several preclinical studies using aqueous or hydroalcoholic extracts of stem bark, leaves, or fruits have reported different actions, including antiulcerative $(4,5)$, anti-inflammatory and anti-nociceptive (6-8), and antioxidative $(8,9)$. The compound Pauferrol A, a chalcone isolated from the stem (10) has shown anticancer actions, as have polar extracts (hexane, chloroform, acetate, and hydroalcoholic) of fruits (11). Hypotensive (12) and anti-hyperglycemic (13) actions have also been reported with the stem bark aqueous extract.

Phytochemical screening of the hydroalcoholic extract of the stem bark and leaves of $L$. ferrea demonstrated the presence of tannins, phenolic compounds, saponins, coumarins, and steroids $(14,15,16)$. The pharmacological properties, botanical aspects, and phytochemical composition of this species have been summarized in greater detail in earlier publications $(17,18)$. Despite the set of preclinical evidence regarding efficacy, few studies related to safety were found in our review of the literature.

\section{Introdução}

O Brasil possui uma rica fauna e flora distribuída nos biomas Amazônia, Cerrado, Caatinga, Mata Atlântica, Pantanal e Pampa. No sentido de explorar de forma sustentável essa riqueza de biodiversidade, o governo brasileiro criou em 2006, a Política Nacional de Plantas Medicinais e Fitoterápicos cujos pilares são garantir à população brasileira o acesso seguro e o uso racional de plantas medicinais e fitoterápicos com segurança, eficácia e qualidade dentro do Sistema Único de Saúde (SUS), desenvolver a cadeia produtiva e da indústria nacional por meio do intercâmbio entre a academia e a iniciativa privada (1).

As espécies de preferência nativas que possuem evidências robustas de eficácia são sistematicamente elencadas para compor a Relação Nacional de Plantas Medicinais de Interesse ao Sistema Único de Saúde (Renisus) na concepção de ampliar as pesquisas direcionadas a cadeia produtiva em fitoterápicos e atenção básica em saúde (2).

Dentre essas espécies encontra-se Libidibia ferrea var. parvifolia (Mart. ex Tul.) L.P. Queiroz (Leguminosae), cujo basiônimo é Caesalpinia ferrea Mart. ex Tul (Caesalpinaceae) (3). Conhecida popularmente como "pau-ferro" ou "jucá", encontra-se distribuída nas regiões Norte e Nordeste do Brasil. Na medicina popular, várias partes da planta como frutos, folhas, sementes e caules de $L$. ferrea são empregadas para tratar múltiplas doenças. Uma característica sui generis que atesta sua potencialidade como candidata a fitoterápico. De fato, vários estudos pré-clínicos usando extratos aquosos ou hidroalcoólicos da casca do caule, folhas ou frutos relataram diferentes ações, incluindo antiulcerativa $(4,5)$, anti-inflamatória e antinociceptiva (6-8) e antioxidante $(8,9)$. O composto Pauferrrol A, uma chalcona isolada do caule (10), apresentou ações anticâncer, assim como, os extratos polares (hexano, clorofórmio, acetato e hidroalcoólico) das frutas (11). Ações hipotensivas (12) e anti-hiperglicêmicas (13) também foram descritas com o extrato aquoso da casca do caule.

A triagem fitoquímica do extrato hidroalcóolico da casca, folhas, fruto e caule de L. ferrea tem sido bastante explorada e demonstrou a presença de taninos, compostos fenólicos, saponinas, cumarinas e esteroides $(14,15,16)$. Para informações mais detalhadas acerca das propriedades farmacológicas, aspectos botânicos e composição fitoquímica dessa espécie pode ser consultada as revisões $(17,18)$. Apesar do conjunto de evidências pré-clínicas quanto à eficácia, o mesmo 
The administration of the stem of $L$. ferrea hydroalcoholic extract $(400 \mathrm{mg} / \mathrm{kg}$, orally) for 30 intermittent days in rats did not induce any sign of toxicity on the body mass, water, and feed consumption or tissue weights (19).

Peter et al. (20) showed that the fruit aqueous extract of $L$. ferrea $(300 \mathrm{mg} / \mathrm{kg}$, orally) did not interference with the implantation of a blatocyst in Wistar rats. However, Pickler et al. (21) verified that the treatment with hydroalcoholic extracts of the seeds and bark of L. ferrea $(1.0 \mathrm{~g} / \mathrm{kg}$, orally) during the gestation period in rats promoted a reduction in the head and body lengths of the fetuses and showed visceral and skeletal anomalies. In the genetrix, there were changes in serum creatinine levels and the production of amniotic fluid of abnormal biochemical composition.

Lucinda et al. (22) reported that the administration of the aqueous extract of the fruits of $L$. ferrea $(300 \mathrm{mg} /$ $\mathrm{kg}$, orally) for 52 and 104 consecutive days did not produce changes in the reproductive system of Wistar rats. In the zebra fish model, the fruit hydroalcoholic extract $(2 \mathrm{~g} / \mathrm{kg})$ did not produce toxicity (16).

Considering the limited information concerning preclinical safety of the species, this study aimed to evaluate the repeated dose toxicity of the stem bark aqueous extract of Libidibia ferrea as part of the process of discovery and development of candidates for herbal medicament trials.

\section{Material and Methods}

\section{Plant material, extraction, and phytochemical}

The bark from the stem of Libidibia ferrea was obtained from an experimental culture from Amazon Research National Institute (INPA), $03^{\circ} 05^{\prime} 48.0^{\prime \prime} \mathrm{S}$, and 59 59' 55.0" W. Gr., Manaus, Amazonas, Brazil. The voucher specimen of the plant, collected between 2009 and 2010, was deposited at the INPA herbarium with the number 228022.

The material collected was dried at room temperature for 48 hours, then taken to the oven with air circulation at a temperature of $45 \pm 2{ }^{\circ} \mathrm{C}$ until its weight stabilized. Subsequently, the material was ground in a $1 \mathrm{~mm}$ mesh knife mill, thus taking the raw materia. The aqueous extract of L. ferrea was prepared by infusing raw material (7.5: 100, w/v) using boiling distilled water as an extractive solvent for a period of 15 minutes. The aqueous extract presented a soluble solid content não se aplica aos estudos de segurança de uso, pois em nossa revisão, os poucos estudos relacionados ao tema foram encontrados.

A administração por 30 dias intermitentes do extrato hidroalcóolico do caule de L. ferrea (400 mg/kg, v.o.) não induziu nenhum sinal de toxicidade em ratos, sobre a massa corporal, consumos de água e ração ou o peso relativo e absoluto dos tecidos (19).

Peter et al. (20) mostraram que o extrato aquoso do fruto de $L$. ferrea $(300 \mathrm{mg} / \mathrm{kg}$, v.o.) não produziu interferência com a implantação de blatocisto em ratas Wistar. Entretanto, Pickler et al. (21) verificaram que o tratamento com os extratos hidroalcoólicos das sementes e da casca ( $1,0 \mathrm{~g} / \mathrm{kg}$, v.o.) de $L$. ferrea durante o período da gestação em ratas promoveu redução no comprimentos dos fetos na cabeça e no corpo e exibiram anomalias viscerais e esqueléticas. Já nas genetrizes houve alterações nos níveis de creatinina sérica e produção de líquido amniótico de composição bioquímica anormal.

Lucinda et al. (22) reportaram que a administração do extrato aquoso dos frutos de L. ferrea $(300 \mathrm{mg} /$ $\mathrm{kg}$, v.o.) por 52 e 104 dias consecutivos não produziu alterações no sistema reprodutivo de ratos Wistar. No modelo de peixe zebra, o extrato hidroalcóolico do fruto $(2 \mathrm{~g} / \mathrm{kg})$ não produziu toxicidade (16).

Considerando a carência de informações de segurança pré-clínica da espécie, este estudo teve como objetivo avaliar a toxicidade de dose repetida do extrato aquoso da casca do caule de Libidibia ferrea como parte do processo dentro da cadeia de descoberta e desenvolvimento de candidatos a fitoterápicos, na concepção de subsidiar futuros ensaios clínicos.

\section{Material e Métodos}

\section{Material vegetal, extração e fitoquímica}

A casca do caule de Libidibia ferrea foi obtida por meio de cultura experimental do Instituto Nacional de Pesquisa da Amazônia (INPA), $03^{\circ} 05^{\prime} 48,0^{\prime \prime} \mathrm{S}$ e $59^{\circ} 59^{\prime}$ 55,0" W. Gr., Manaus, Amazonas, Brasil. Uma amostra da planta coletada entre 2009 e 2010 foi depositada no herbário do INPA com o n 228022.

O material coletado foi seco em temperatura ambiente por $48 \mathrm{~h}$, em seguida levado ao forno com circulação de ar a uma temperatura de $45 \pm 2^{\circ} \mathrm{C}$ até a estabilização do peso. Posteriormente, o material foi moído em um moinho de faca de malha de $1 \mathrm{~mm}$, obtendo-se a 
of $0.60 \pm 0.02 \%$, which was determined in triplicate through loss by drying in an oven until a constant weight. The aqueous extract was dried using an MSD 1.0 Labmaq Mini Spray Dryer (inlet temperature: 120 ${ }^{\circ} \mathrm{C}$, compressed air pressure: $2 \mathrm{bar}, 0.7 \mathrm{~mm}$ diameter impeller:0.7 $\mathrm{mm}$, and power flow: $10 \mathrm{~mL} / \mathrm{min}$ ). The yield of dry extract after drying of aqueous extract was $98 \%$. The chromatogram of the extract was previously reported (13). In summary, the chemical identification of the constituents of L. ferrea bark revealed the presence of condensed tannins (catechins) and hydrolyzable tannins (gallic acid and ellagic acid). The total tannin content of L. ferrea spray-dried extract was calculated at $266 \mathrm{mg} / \mathrm{g}$. In addition, the values obtained by highperformance liquid chromatography of gallic acid, catechin, epicatechin, and ellagic acid were 112.8, 17.8, 6.1 , and $12.0 \mathrm{mg} / \mathrm{g}$ respectively.

\section{Animals}

All experimental protocols were submitted to and approved by the Animal Experimentation Ethics Committee of Federal University of Pernambuco (UFPE, license $n^{\circ}$. 01411), in accordance with the National Institutes of Health's (23) Guide for the Care and Use of Laboratory Animals. Male Swiss mice (aged 2-3 months, weighing 45-50 g) were obtained from the vivarium of the Department of Physiology and Pharmacology at the UFPE, Pernambuco, Brazil. The animals were kept under standard environmental conditions $\left(22 \pm 2{ }^{\circ} \mathrm{C} ; 12: 12 \mathrm{~h}\right.$ dark/light cycle and humidity 55-65\%). Water and standard food (Presence, Purina, São Paulo, Brazil) were made available ad libitum.

\section{Treatment}

Healthy mice were randomly divided into three groups ( $n=10$ /group). The animals were treated orally with vehicle (water) and stem bark aqueous extract of $L$. ferrea at 300 and $1500 \mathrm{mg} / \mathrm{kg}$ bw/day, for 12 weeks. The extract was freshly prepared daily and administered by gavage at a proportion of $0.1 \mathrm{~mL} / 10 \mathrm{gbw}$ within 2 hours. Dose selection used in this study (1 and 5 times) was based on the lowest dose of L. ferrea $(300 \mathrm{mg} / \mathrm{kg}$ ) that showed antihyperglycemic activity as published by our group (13). matéria-prima vegetal. O extrato aquoso de $L$. ferrea foi preparado por infusão de matéria-prima (7,5: 100, $\mathrm{p} / \mathrm{v}$ ) usando água destilada fervente como solvente extrativo por um período de 15 minutos. O extrato aquoso apresentou teor de sólidos solúveis de $0,6 \pm$ $0,02 \%$ que foi determinado em triplicata por meio de perda por dessecação em estufa até obtenção de peso constante. O extrato aquoso foi seco usando um MSD 1.0 Labmaq Mini Spray Dryer (temperature de entrada: $120^{\circ} \mathrm{C}$, pressão de ar comprimido: 2 bar, rotor de diâmetro: $0,7 \mathrm{~mm}$ e fluxo de energia: $10 \mathrm{~mL} / \mathrm{min}$ ). $\mathrm{O}$ rendimento do extrato seco após secagem do extrato aquoso foi de $98 \%$. O cromatograma do extrato foi previamente relatado (13). Em resumo, a identificação química dos constituintes da casca de $L$. ferrea revelou a presença de taninos condensados (catequinas) e taninos hidrolisáveis (ácido gálico e ácido elágico). O teor total de tanino do extrato seco por pulverização de $L$. ferrea foi calculado em $266 \mathrm{mg} / \mathrm{g}$. Além disso, os valores obtidos por cromatografia líquida de alta eficiência de ácido gálico, catequina, epicatequina e ácido elágico foram 112,$86 ; 17,8 ; 6,1$ e 12,0 mg/g, respectivamente.

\section{Animais}

Todos os protocolos experimentais foram submetidos e aprovados pelo Comitê de Ética em Experimentação Animal da Universidade Federal de Pernambuco (UFPE, licença $\mathrm{n}^{\circ}$ 01411), de acordo com o Guia do Instituto Nacional de Saúde (23) para o cuidado e uso de animais de laboratório. Camundongos Suíços machos (com idade entre 2 e 3 meses, pesando $45-50 \mathrm{~g}$ ) foram obtidos no biotério do Departamento de Fisiologia e Farmacologia da UFPE, Pernambuco, Brasil. Os animais foram mantidos em condições ambientais padrão $\left(22 \pm 2{ }^{\circ} \mathrm{C} ; 12: 12 \mathrm{~h}\right.$ ciclo claro/escuro e umidade 55-65\%). Água e ração padrão (Presença, Purina, São Paulo, Brasil) foram disponibilizados ad libitum.

\section{Tratamento}

Camundongos sadios foram divididos aleatoriamente em três grupos $(\mathrm{n}=10$ /grupo). Os animais foram tratados oralmente com veículo (água) e extrato aquoso da casca do caule de L. ferrea (300 e $1500 \mathrm{mg} /$ $\mathrm{kg}$ pc/dia), por 12 semanas. O extrato foi preparado diariamente e administrado dentro de um período de 2 horas, por gavagem em uma proporção de $0,1 \mathrm{~mL} / 10$ g pc. A seleção da dose utilizada neste estudo (1 e 5 vezes) foi baseada na dose mais baixa de $L$. ferrea (300 $\mathrm{mg} / \mathrm{kg}$ ) que apresentou atividade anti-hiperglicêmica, conforme publicado por nosso grupo (13). 
Evaluation of the body weight gain, water, and food intake

The animals were observed daily for signs of toxicity, such as piloerection, stereotyped movements, convulsions, catatonia, diarrhea, and mortality throughout the experimental period (24). They were weighed initially and then once a week throughout the study and before euthanasia. The amount of supplied and residual water or food was weighed once a week to calculate the average consumption each week. At the end of the 12-week experiment, the animals fasted overnight, although the water was made available ad libitum. They were then anesthetized with thiopental (35 mg/kg, i.p.) and blood samples were obtained by retro-orbital puncture using capillary tubes and collected in two tubes: i) tube containing anticoagulant ethylenediaminetetraacetic acid, ii) tube without anticoagulant for hematological and biochemical parameters, respectively (25).

\section{Hematological and biochemical analysis}

The hematological analysis was performed using an automatic hematological analyzer (Coulter STKS, Beckman, CA, USA). Parameters included: red blood cell (RBC) count, hemoglobin, hematocrit, mean corpuscular volume (MCV), mean corpuscular hemoglobin $(\mathrm{MCH})$, mean corpuscular hemoglobin concentration (MCHC), red cell distribution width (RDW), platelets count, mean platelet volume (MPV), and white blood cell (WBC) count. The differential leukocyte count was performed with optical microscopy after staining and, in each case, 100 cells were counted. For biochemical analysis, blood was centrifuged at $1480 \times \mathrm{g}$ for $10 \mathrm{~min}$ to obtain serum, which was stored at $-20{ }^{\circ} \mathrm{C}$ until the following parameters were determined: glucose, blood urea nitrogen (BUN), creatinine, aspartate aminotransferase (AST), alanine aminotransferase (ALT), bilirubin (total, direct, and indirect), total protein, albumin, triglyceride, total cholesterol, amylase, uric acid, and lactate dehydrogenase (LDH). Dosages were made using Architect (Abbott, Abbott Park, IL, USA) automation with Boehringer Ingelheim (São Paulo, Brazil) biochemical kits according to the manufacturer's instructions.

\section{Morphological study}

After euthanasia (thiopental, $140 \mathrm{mg} / \mathrm{kg}$, i.p.), half of the animals ( $\mathrm{n}=5 /$ group) were randomly selected for macroscopic external evaluation of the heart, kidney, lung, liver, stomach, small intestine, pancreas, testicle, epididymis, seminal vesicle and vas deferens. These
Avaliação do ganho de massa corporal, água e ingestão de ração

Os animais foram observados diariamente quanto a sinais de toxicidade, como piloereção, movimentos estereotipados, convulsões, catatonia, diarreia e mortalidade durante todo o período experimental (24). Os animais foram pesados inicialmente e posteriormente uma vez por semana durante todo o estudo, e antes da eutanásia. O volume de água e a quantidade de ração fornecida e residual foi pesada uma vez por semana para calcular o consumo médio a cada semana. Ao final da $12^{\circ}$ semana, os animais foram deixados em jejum durante a noite, mas com água ad libitum. Eles foram anestesiados com tiopental (35 mg/kg, i.p.) e as amostras de sangue foram obtidas por punção retroorbital usando tubos capilares e coletadas em dois tubos: o primeiro, contendo o anticoagulante ácido etilenodiaminotetraacético (EDTA) e o segundo tubo sem anticoagulante para determinação dos parâmetros hematológicos e bioquímicos, respectivamente (25).

\section{Análises hematológica e bioquímica}

A análise hematológica foi realizada utilizando um analisador hematológico automático (Coulter STKS, Beckman, CA, EUA). Parâmetros incluídos: contagem de glóbulos vermelhos (hemácias), hemoglobina, hematócrito, volume corpuscular médio (MCV), hemoglobina corpuscular média $(\mathrm{MCH})$, concentração média de hemoglobina corpuscular (MCHC), largura de distribuição de glóbulos vermelhos (RDW), contagem de plaquetas, plaqueta média volume (MPV) e contagem de glóbulos brancos (WBC). A contagem diferencial de leucócitos foi realizada com microscopia óptica após coloração e, em cada caso, 100 células foram contadas. Para análise bioquímica, o sangue foi centrifugado a $1480 \times g$ por 10 min para obter soro, que foi armazenado a $-20^{\circ} \mathrm{C}$ até que os seguintes parâmetros fossem determinados: glicose; nitrogênio da ureia no sangue (BUN); creatinina; aspartato aminotransferase (AST); alanina aminotransferase (ALT); bilirrubina total, direta e indireta, proteína total; albumina; triglicerídeo; colesterol total; amilase; ácido úrico e lactato desidrogenase (LDH). As dosagens foram feitas usando a automação Architect (Abbott, IL, EUA) com kits bioquímicos Boehringer Ingelheim (São Paulo, Brasil), de acordo com as instruções do fabricante.

\section{Estudos morfológicos}

Após a eutanásia (tiopental, $140 \mathrm{mg} / \mathrm{kg}$, i.p.), metade dos animais ( $\mathrm{n}=5 /$ grupo) foi selecionada aleatoriamente para avaliação macroscópica externa do coração, 
tissues were carefully removed, washed in $0.9 \% \mathrm{NaCl}$ solution, and placed on filter paper to remove excess humidity, after which they weighed on an analytical balance. The organ weights were expressed in absolute and relative terms ( $\mathrm{g}$ and $\mathrm{g} / 100 \mathrm{~g}$ of body weight, respectively). Histological examination was then performed on the remaining mice ( $\mathrm{n}=5$ /group). Animals were anesthetized, perfused by intracardiac route with $0.9 \% \mathrm{NaCl}$ solution (for removal of blood) followed by buffered formalin solution (10\%) for $10 \mathrm{~min}$. The same organs were removed and fixed in Bouin solution for $48 \mathrm{~h}$ at room temperature. Tissue slices were processed and stained with hematoxylin/eosin (26).

\section{Statistical analysis}

Values were expressed as mean \pm standard error of the mean (S.E.M). Statistical analysis was performed using Prism 8.0 (GraphPad Software, Inc., La Jolla, CA, USA). The level of significance for rejection of the null hypothesis was set at 5\% $(p<0.05)$. Assuming Gaussian distribution of residues, the differences between groups were determined by oneway analysis of variance (ANOVA), assuming equal standard deviations (homogeneity) and followed, when necessary, by Dunnett's multiple comparisons test. The Prism program option to discard outliers was not used.

\section{Results}

\section{Body weight gain, food and water intake}

During the treatment period, no animals died. In addition, there were no changes in the behavior pattern or signs of toxicity in the animals in relation to the control group.

As can be seen in Figure 1A, the groups treated with $L$. ferrea did not show the body weight gain presented by the control group. Instead, the groups treated with $L$. ferrea exhibit a significant loss in the body weight in the initial phase (four weeks) of the treatment, and by the seventh week, their body weight stabilized.

Figures $1 \mathrm{~B}$ and $1 \mathrm{C}$, show a variation in the food and water intake in the group receiving both doses of $L$. ferrea when compared to the control group. There was rim, pulmão, fígado, estômago, intestino delgado, pâncreas, testículo, epidídimo, vesícula seminal e ducto deferente. Esses tecidos foram cuidadosamente removidos, lavados em solução de $\mathrm{NaCl}$ a $0,9 \%$ e colocados em papel de filtro para remover o excesso de umidade e depois pesados em uma balança analítica. As massas dos órgãos foram expressas em termos absolutos e relativos (g e g/100 g de massa corporal, respectivamente). $\mathrm{O}$ exame histológico foi realizado nos demais camundongos ( $\mathrm{n}=5$ /grupo). Os animais foram anestesiados, perfundidos por via intracardíaca com solução de $\mathrm{NaCl}$ a $0,9 \%$ (para remoção de sangue), seguida de solução de formalina tamponada (10\%) por $10 \mathrm{~min}$. Os mesmos órgãos foram removidos e fixados em solução de Bouin por $48 \mathrm{~h}$ em temperatura ambiente. Os cortes histológicos foram processados e corados com hematoxilina/eosina (26).

\section{Análise estatística}

Os valores foram expressos como média \pm erro padrão da média (E.P.M). A análise estatística foi realizada usando o Prism 8.0 (GraphPad Software, Inc., La Jolla, CA, EUA). O nível de significância para rejeição da hipótese nula foi estabelecido em $5 \%(\mathrm{p}<0,05)$. Assumindo a distribuição Gaussiana de resíduos, as diferenças entre os grupos foram determinadas pela análise de variância de uma via (ANOVA), assumindo desvios padrões iguais (homogeneidade) e seguida, quando necessário, pelo teste de comparações múltiplas de Dunnett. A opção do programa Prism para descartar valores atípicos não foi usada.

\section{Resultados}

\section{Ganho de massa corporal, consumo de ração e água}

Durante o período de tratamento, nenhum animal morreu. Além disso, não houve alterações no padrão de comportamento ou sinais de toxicidade nos animais em relação ao grupo controle.

Como pode ser visto na Figura 1A, os grupos tratados com L. ferrea não apresentaram ganho de massa corporal observado no grupo controle. Em vez disso, os grupos tratados com L. ferrea mostraram uma perda significativa de massa corporal na fase inicial (quatro semanas) do tratamento e, na sétima semana, tiveram sua massa corporal estabilizado.

As Figuras 1B e 1C mostram uma variação na ingestão de ração e água no grupo que receberam as duas doses 

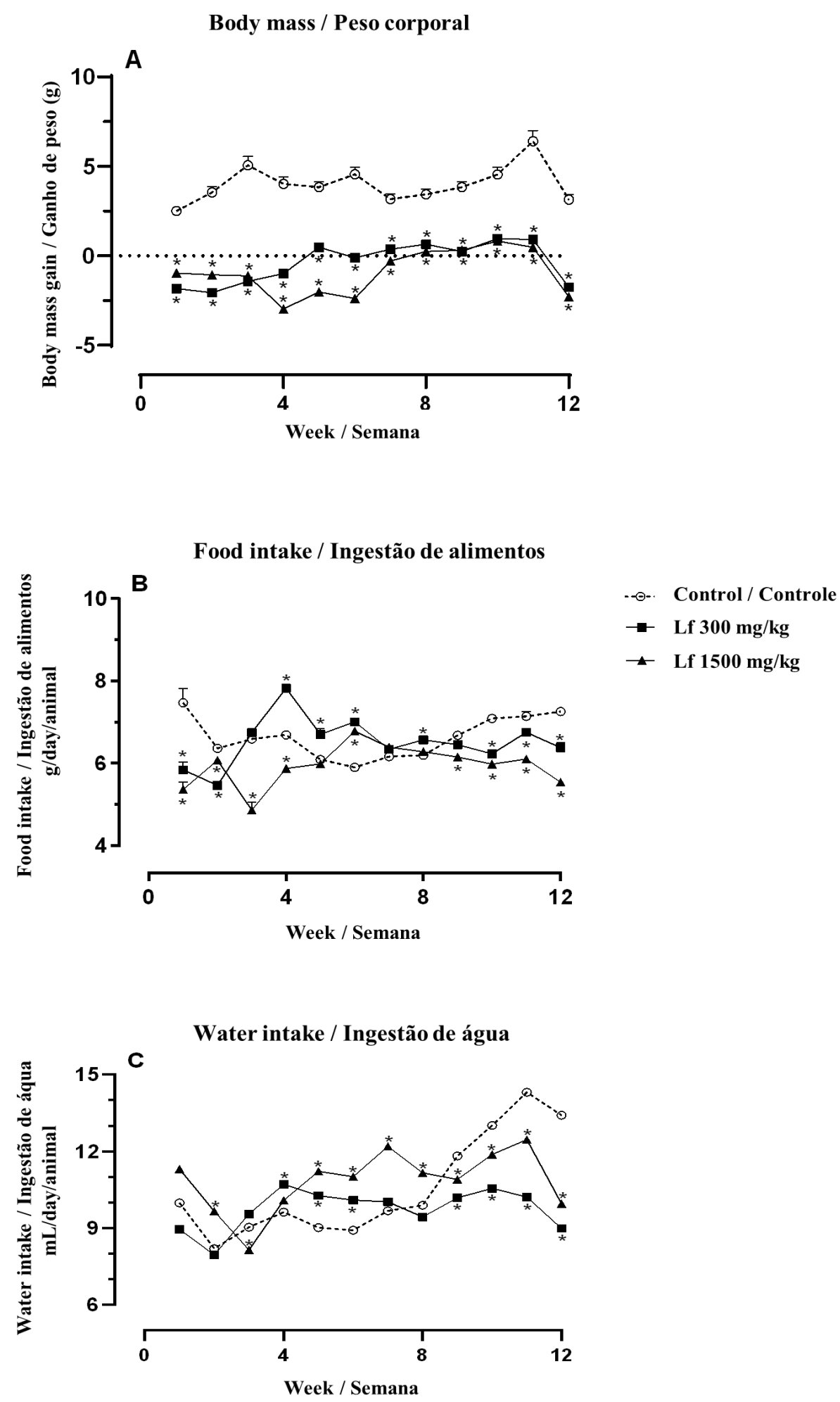

Figure 1 - Effect of aqueous extract of Libidibia ferrea (Lf, $1500 \mathrm{mg} / \mathrm{kg} /$ day for 12 weeks) on body mass gain (A), food intake(B) and water intake (C) of mice. The results are expressed as mean \pm S.E.M. $(n=10 /$ group). *Statistically different from control group, $\mathrm{p}<0.05$ (one-way ANOVA, followed by Dunnett's multiple comparisons test).

Figura 1 - Efeito do extrato aquoso de Libidibia ferrea (Lf, $1500 \mathrm{mg} / \mathrm{kg} /$ dia por 12 semanas) no ganho de massa corporal (A), ingestão de alimentos (B) e ingestão de água (C) de camundongos. Os resultados são expressos como média \pm E.P.M. ( $n=10$ /grupo). *Estatisticamente diferente do grupo controle, $\mathrm{p}<0,05$ (ANOVA de uma via, seguida pelo teste de comparações múltiplas de Dunnett). 
Table 1 - Effect of treatment with aqueous extract of Libidibia ferrea (Lf, 300, and $1500 \mathrm{mg} / \mathrm{kg}$ ) on organ weight of mice for 12 weeks. The values represent mean \pm SEM. ( $n=5$ /group).

Tabela 1 - Efeito do tratamento com extrato aquoso de Libidibia ferrea (Lf, 300 e $1500 \mathrm{mg} / \mathrm{kg}$ ) sobre o peso dos órgãos de camundongos por 12 semanas. Os valores representam a média \pm EPM. ( $n=5 /$ grupo).

\begin{tabular}{|c|c|c|c|}
\hline $\begin{array}{l}\text { Absolute organ weight / } \\
\text { Peso absoluto dos órgãos (g) }\end{array}$ & $\begin{array}{l}\text { Control/ } \\
\text { Controle }\end{array}$ & Lf $300 \mathrm{mg} / \mathrm{kg}$ & Lf $1500 \mathrm{mg} / \mathrm{kg}$ \\
\hline Heart / Coração & $0.23 \pm 0.01$ & $0.23 \pm 0.01$ & $0.18 \pm 0.01$ \\
\hline Kidney / Rim & $0.33 \pm 0.01$ & $0.33 \pm 0.01$ & $0.30 \pm 0.01$ \\
\hline Lung / Pulmão & $0.28 \pm 0.01$ & $0.26 \pm 0.01$ & $0.27 \pm 0.01$ \\
\hline Liver / Fígado & $2.35 \pm 0.17$ & $2.18 \pm 0.10$ & $2.22 \pm 0.11$ \\
\hline Stomach / Estômago & $0.30 \pm 0.03$ & $0.33 \pm 0.01$ & $0.34 \pm 0.02$ \\
\hline Small intestine / Intestino Delgado & $2.44 \pm 0.27$ & $3.14 \pm 0.26$ & $3.14 \pm 0.26$ \\
\hline Pancreas / Pâncreas & $0.27 \pm 0.02$ & $0.29 \pm 0.02$ & $0.26 \pm 0.03$ \\
\hline Testicle / Testículo & $0.136 \pm 0.007$ & $0.122 \pm 0.004$ & $0.120 \pm 0.010$ \\
\hline Epididymis / Epidídimo & $0.054 \pm 0.004$ & $0.049 \pm 0.002$ & $0.058 \pm 0.002$ \\
\hline Seminal vesicle / Vesícula seminal & $0.32 \pm 0.02$ & $0.31 \pm 0.01$ & $0.25 \pm 0.01^{*}$ \\
\hline Vas deferens / Ducto deferente & $0.019 \pm 0.001$ & $0.019 \pm 0.001$ & $0.015 \pm 0.001$ \\
\hline $\begin{array}{l}\text { Relative organ weight / } \\
\text { Peso relativo dos órgãos (g/100g) }\end{array}$ & $\begin{array}{l}\text { Control / } \\
\text { Controle }\end{array}$ & Lf 300 mg/kg & Lf $1500 \mathrm{mg} / \mathrm{kg}$ \\
\hline Heart / Coração & $0.49 \pm 0.02$ & $0.56 \pm 0.02 *$ & $0.43 \pm 0.02$ \\
\hline Kidney / Rim & $0.70 \pm 0.02$ & $0.78 \pm 0.01^{*}$ & $0.72 \pm 0.01$ \\
\hline Lung / Pulmão & $0.57 \pm 0.05$ & $0.42 \pm 0.03^{*}$ & $0.48 \pm 0.04$ \\
\hline Liver / Fígado & $4.96 \pm 0.46$ & $5.09 \pm 0.19$ & $5.36 \pm 0.22$ \\
\hline Stomach / Estômago & $0.62 \pm 0.04$ & $0.78 \pm 0.03^{*}$ & $0.82 \pm 0.05^{*}$ \\
\hline Small intestine / Intestino Delgado & $4.35 \pm 0.59$ & $4.79 \pm 0.27$ & $7.62 \pm 0.66^{*}$ \\
\hline Pancreas / Pâncreas & $0.56 \pm 0.03$ & $0.68 \pm 0.06$ & $0.62 \pm 0.07$ \\
\hline Testicle / Testículo & $0.28 \pm 0.01$ & $0.28 \pm 0.01$ & $0.33 \pm 0.02$ \\
\hline Epididymis / Epidídimo & $0.111 \pm 0.007$ & $0.119 \pm 0.004$ & $0.140 \pm 0.006^{*}$ \\
\hline Seminal vesicle / Vesícula seminal & $0.67 \pm 0.05$ & $0.68 \pm 0.03$ & $0.62 \pm 0.04$ \\
\hline Vas deferens / Ducto deferente & $0.042 \pm 0.004$ & $0.043 \pm 0.004$ & $0.036 \pm 0.004$ \\
\hline
\end{tabular}

*Statistically different from control group, $\mathrm{p}<0.05$ (one-way ANOVA followed by Dunnett's multiple comparisons test) / *Estatisticamente diferente do grupo controle, $\mathrm{p}<0,05$ (ANOVA de uma via seguida pelo teste de comparações múltiplas de Dunnett).

a discontinuous pattern of the consumption in time course. However, from the ninth week on, the reduction in food and water intake was evident until the end of the treatment.

\section{Tissues weight}

The effects of $L$. ferrea on absolute and relative organ weights are shown in Table 1. The external analysis of the tissues heart, kidney, lung, liver, stomach, intestine, pancreas, testis, and epididymis of both groups treated with $L$. ferrea did not show significant alterations in de L. ferrea quando comparado ao grupo controle. Houve um padrão descontínuo do consumo no decorrer do tempo. No entanto, a partir da nona semana, a redução na ingestão de ração e água ficou evidente até o final do tratamento.

\section{Massa dos tecidos}

Os efeitos de $L$. ferrea sobre a massa absoluta e relativa dos órgãos são apresentados na Tabela 1. A análise externa dos tecidos coração, rim, pulmão, fígado, estômago, intestino, pâncreas, testículo e epidídimo 
weight, color or texture when compared to the control group.

Concerning the absolute organ weights, the treatment with L. ferrea $300 \mathrm{mg} / \mathrm{kg}$ bw/day did not produce significant changes. However, L. ferrea $1500 \mathrm{mg} / \mathrm{kg}$ bw/day induced a decrease of $21.9 \%$ and $21.1 \%$ of the seminal vesicle and vas deferens, respectively.

The administration of L. ferrea $300 \mathrm{mg} / \mathrm{kg}$ bw/day produced an increase in the relative weight for the heart $(14.2 \%)$, kidney $(11.4 \%)$, and stomach $(25.8 \%)$ organs. A reduction in lung weight $(26.3 \%)$ was also recorded.

The highest dose of the extract $(1500 \mathrm{mg} / \mathrm{kg})$ produced a significant increase of $32.2,75.2$, and $17.8 \%$ in the relative masses of the stomach, small intestine, and testis respectively.

\section{Histopathological analysis of organs}

All organs examined were normal, except for the kidney that presented a mild leucocyte infiltrate, and the intestine, which presented an intraepithelial leucocyte infiltrate and areas of necrosis (Figure 2).

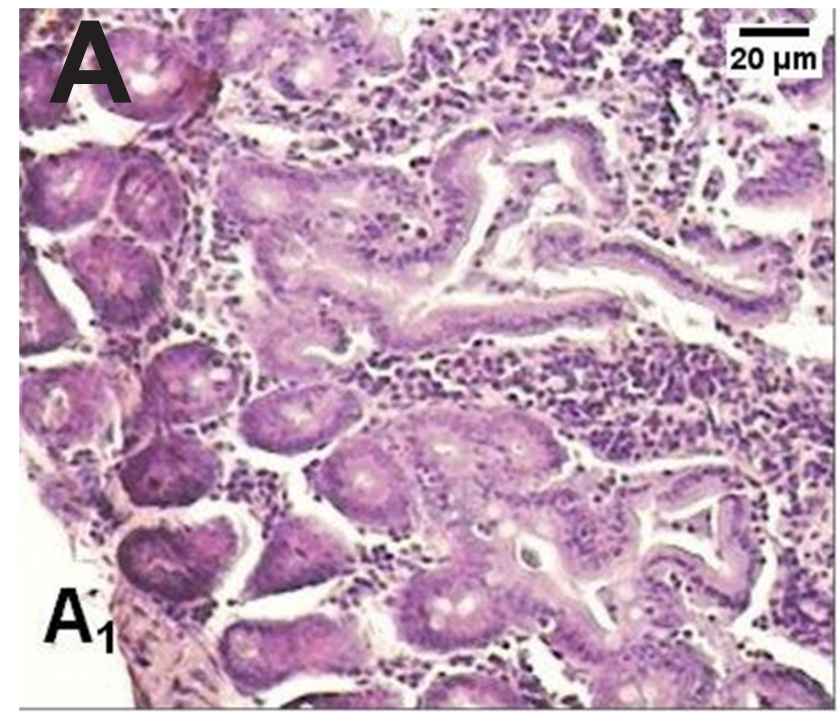

de ambos os grupos tratados com $L$. ferrea não apresentaram alterações significativas na massa, cor ou textura quando comparados ao grupo controle.

Em relação a massa absoluta dos órgãos, o tratamento com L. ferrea $300 \mathrm{mg} / \mathrm{kg}$ pc/dia não produziu alteração significativa. No entanto, L. ferrea $1500 \mathrm{mg} / \mathrm{kg} \mathrm{pc} /$ dia induziu diminuição $(21,9 \%$ e $21,1 \%)$ da massa da vesícula seminal e do ducto deferente, respectivamente.

A administração de L. ferrea $300 \mathrm{mg} / \mathrm{kg}$ pc/dia produziu aumento na massa relativa do coração $(14,2 \%)$, rim $(11,4 \%)$ e estômago $(25,8 \%)$. Além disso, houve redução $(26,3 \%)$ na massa do tecido pulmonar. Já a maior dose do extrato $(1500 \mathrm{mg} / \mathrm{kg})$ produziu aumento significativo de 32,2; 75,2 e 17,8\% nas massas relativas do estômago, intestino delgado e testículo respectivamente.

\section{Análise histopatológica dos órgãos}

Todos os órgãos examinados mostraram aspectos normais, exceto o rim que apresentou leve infiltrado de leucócitos e o intestino, onde observou-se infiltrado de leucócitos intraepitelial e áreas de necrose (Figura 2).

Figure 2 - Histological sections of intestine (A) and kidney (B) of mice treated with L. ferrea (1500 mg/ $\mathrm{kg} /$ day for 12 weeks) (HE) $-\mathrm{A}_{1}$ and $\mathrm{A}_{2}$ : areas of leukocyte infiltrate and necrosis in intestine and kidney (Magnification: 200x[A $]$, 400x[A $]$ ).

Figura 2 - Cortes histológicos do intestino (A) e rim (B) de camundongos tratados com L. ferrea (1500 $\mathrm{mg} / \mathrm{kg}$ / dia por 12 semanas) (HE) - $\mathrm{A}_{1}$ e $\mathrm{A}_{2}$ : áreas de infiltrado de leucócitos e necrose no intestino e rim (Ampliação: 200x [A $]$, 400x [A $\left.\mathrm{A}_{2}\right]$ ). 
Table 2 - Effect of treatment with aqueous extract of Libidibia ferrea (Lf, 300, and $1500 \mathrm{mg} / \mathrm{kg}$ ) on biochemical parameters in mice for 12 weeks. The values represent mean \pm SEM. ( $n=10 /$ group).

Tabela 2 - Efeito do tratamento com extrato aquoso de Libidibia ferrea (Lf, 300 e $1500 \mathrm{mg} / \mathrm{kg}$ ) nos parâmetros bioquímicos de camundongos por 12 semanas. Os valores representam a média \pm EPM. ( $\mathrm{n}=10$ /grupo).

\begin{tabular}{|c|c|c|c|}
\hline $\begin{array}{l}\text { Biochemical parameter / } \\
\text { Parâmetro bioquímico }\end{array}$ & $\begin{array}{l}\text { Control / } \\
\text { Controle }\end{array}$ & Lf $300 \mathrm{mg} / \mathrm{kg}$ & Lf 1500 mg/kg \\
\hline Glucose / Glicose (mg/dL) & $90.13 \pm 7.47$ & $96.75 \pm 5.63$ & $90.38 \pm 4.88$ \\
\hline Blood Urea Nitrogen / & $56.25 \pm 2.19$ & $49.50 \pm 1.55^{*}$ & $54.25 \pm 1.57$ \\
\hline \multicolumn{4}{|l|}{ Ureia Nitrogenada no Sangue (mg/dL) } \\
\hline Creatinine / Creatinina (mg/dL) & $0.20 \pm 0.02$ & $0.20 \pm 0.02$ & $0.24 \pm 0.02$ \\
\hline Total bilirubin / Bilirrubina total (mg/dL) & $0.16 \pm 0.04$ & $0.14 \pm 0.02$ & $0.15 \pm 0.02$ \\
\hline Direct bilirubin / Bilirrubina direta (mg/dL) & $0.12 \pm 0.02$ & $0.11 \pm 0.01$ & $0.12 \pm 0.02$ \\
\hline Indirect bilirubin / Bilirrubina Indireta $(\mathrm{mg} / \mathrm{dL})$ & $0.04 \pm 0.03$ & $0.02 \pm 0.02$ & $0.02 \pm 0.01$ \\
\hline Triglyceride / Triglicerídeos (mg/dL) & $103.10 \pm 6.19$ & $115.10 \pm 8.20$ & $111.60 \pm 6.75$ \\
\hline Total cholesterol / Colesterol total (mg/dL) & $112.90 \pm 3.91$ & $112.30 \pm 3.19$ & $102.00 \pm 3.24$ \\
\hline Uric acid / Ácido úrico (mg/dL) & $2.40 \pm 0.19$ & $2.34 \pm 0.20$ & $1.97 \pm 0.01$ \\
\hline Total proteins / Proteínas totais (g/L) & $5.07 \pm 0.06$ & $4.79 \pm 0.06^{*}$ & $4.54 \pm 0.07^{*}$ \\
\hline Albumin / Albumina (g/L) & $2.86 \pm 0.13$ & $2.46 \pm 0.07^{*}$ & $2.35 \pm 0.12$ \\
\hline $\begin{array}{l}\text { Alanine aminotransferase / } \\
\text { Alanina aminotransferase (U/L) }\end{array}$ & $34.63 \pm 4.73$ & $32.38 \pm 2.56$ & $42.75 \pm 2.25$ \\
\hline $\begin{array}{l}\text { Aspartate aminotransferase / } \\
\text { Aspartato aminotransferase (U/L) }\end{array}$ & $80.75 \pm 6.80$ & $125.20 \pm 11.12^{*}$ & $143.01 \pm 11.26^{*}$ \\
\hline $\begin{array}{l}\text { Lactate dehydrogenase / } \\
\text { Lactato desidrogenase (U/L) }\end{array}$ & $370.4 \pm 25.3$ & $322.1 \pm 15.5$ & $517.5 \pm 19.4^{*}$ \\
\hline Amylase / Amilase (U/L) & $1000.0 \pm 15.5$ & $1190.1 \pm 13.1^{*}$ & $1375.1 \pm 14.9 *$ \\
\hline
\end{tabular}

*Statistically different from control group, $\mathrm{p}<0.05$ (one-way ANOVA followed by Dunnett's multiple comparisons test) /

*Estatisticamente diferente do grupo controle, $\mathrm{p}<0,05$ (ANOVA de uma via seguida pelo teste de comparações múltiplas de Dunnett).

\section{Biochemical and hematological analysis}

Regarding the biochemical parameters (Table 2), no statistical differences were observed in the serum levels of glucose, creatinine, total bilirubin, direct bilirubin, and indirect bilirubin, triglyceride, total cholesterol, uric acid, and alanine aminotransferase (ALT). However, the mice treated with $L$. ferrea $300 \mathrm{mg} / \mathrm{kg}$ bw/day showed a reduction $(12 \%)$ in the serum levels of urea value. The groups treated with extract (300 and $1500 \mathrm{mg} / \mathrm{kg}$ bw/day) presented a diminution in total proteins (5.5 and $10.5 \%$ ), and albumin (14 and 17.8\%) levels, and a significant increase in aspartate aminotransferase (AST, 55.0 and $77.1 \%)$ and amylase (19.0 and 37.5\%) levels respectively, in comparison to the control group. A marked increase of $39.7 \%$ in the lactate dehydrogenase (LDH) level was observed in the $1500 \mathrm{mg} / \mathrm{kg} \mathrm{bw} /$ day L. ferrea group.

\section{Análises bioquímicas e hematológicas}

Em relação aos parâmetros bioquímicos (Tabela 2), não foram observadas diferenças estatísticas nos níveis séricos de glicose, creatinina, bilirrubinas total, direta e indireta, triglicerídeos, colesterol total, ácido úrico e alanina aminotransferase (ALT). Contudo, os camundongos tratados com L. ferrea $300 \mathrm{mg} / \mathrm{kg} \mathrm{pc} /$ dia mostraram uma redução (12\%) nos níveis séricos do valor de ureia. Os grupos tratados com extrato apresentaram uma diminuição nos níveis de proteínas totais $(5,5$ e $10,5 \%)$ e albumina (14 e 17,8\%) e um aumento importante respectivamente nos níveis de aspartato aminotransferase (AST, 55 e 77,1\%) e amilase (19 e 37,5\%), em comparação ao grupo controle. O grupo L. ferrea $1500 \mathrm{mg} / \mathrm{kg} \mathrm{pc} /$ dia induziu um aumento acentuado de 39,7\% no nível de lactato desidrogenase (LDH). 
Hematological parameters of L. ferrea-treated mice are summarized in Table 3. The erythrocyte count, hematocrit, and hemoglobin concentration were not altered by the treatment with $L$. ferrea. The mean corpuscular volume (MCV) was decreased $(7.5 \%)$ in the group that received L. ferrea $1500 \mathrm{mg} / \mathrm{kg}$ bw/day and the mean corpuscular hemoglobin concentration (MCHC) was increased (1.9 and 2.2\%) in both groups treated with $L$. ferrea. The platelet count was not changed by the treatment. However, there was a decrease $(4.7 \%)$ in mean platelet volume (MPV).

The relative lymphocyte count was increased $(2.3 \%)$ in the group treated with $L$. ferrea $1500 \mathrm{mg} / \mathrm{kg}$ bw/day. In this same group, the leucocyte count had an expressive increase $(67.3 \%)$ and relative neutrophils count had a marked reduced (49.2\%) also when compared to the control group.
Os parâmetros hematológicos dos camundongos tratados com L. ferrea estão resumidos na Tabela 3. A contagem de eritrócitos, hematócrito e concentração de hemoglobina não foram alterados pelo tratamento com L. ferrea. O volume corpuscular médio (MCV) diminuiu (7,5\%) no grupo que recebeu L. ferrea 1500 $\mathrm{mg} / \mathrm{kg} \mathrm{pc} / \mathrm{dia}$ e a concentração média de hemoglobina corpuscular (MCHC) aumentou (1,9 e 2,2\%) em ambos os grupos tratados com L. ferrea. A contagem de plaquetas não foi alterada pelo tratamento. No entanto, houve uma diminuição $(4,7 \%)$ no volume médio de plaquetas (MPV).

A contagem relativa de linfócitos foi aumentada (2,3\%) no grupo tratado com L. ferrea $1500 \mathrm{mg} / \mathrm{kg} \mathrm{pc} / \mathrm{dia}$. Nesse mesmo grupo, a contagem de leucócitos teve um aumento expressivo $(67,3 \%)$ e a contagem relativa de neutrófilos teve uma redução acentuada (49,2\%) também quando comparada ao grupo controle.

Table 3 - Effect of treatment with aqueous extract of Libidibia ferrea (Lf, 300, and $1500 \mathrm{mg} / \mathrm{kg}$ ) on hematological parameters in mice for 12 weeks. The values represent mean \pm SEM. ( $n=10$ /group).

Tabela 3 - Efeito do tratamento com extrato aquoso de Libidibia ferrea (Lf, 300 e $1500 \mathrm{mg} / \mathrm{kg}$ ) nos parâmetros hematológicos de camundongos por 12 semanas. Os valores representam a média \pm EPM. (n = 10/grupo).

\begin{tabular}{|c|c|c|c|}
\hline $\begin{array}{l}\text { Hematological parameter / } \\
\text { Parâmetro hematológico }\end{array}$ & $\begin{array}{l}\text { Control / } \\
\text { Controle }\end{array}$ & Lf $300 \mathrm{mg} / \mathrm{kg}$ & Lf $1500 \mathrm{mg} / \mathrm{kg}$ \\
\hline RBC / Hemácias $\left(10^{6} / \mathrm{mm}^{3}\right)$ & $9.15 \pm 0.40$ & $9.63 \pm 0.28$ & $9.90 \pm 0.15$ \\
\hline Hemoglobin / Hemoglobina (g/dL) & $14.92 \pm 0.76$ & $15.86 \pm 0.38$ & $15.67 \pm 0.16$ \\
\hline Hematocrit / Hematócrito (\%) & $46.51 \pm 0.67$ & $47.63 \pm 1.11$ & $46.68 \pm 0.27$ \\
\hline $\begin{array}{l}\text { Mean corpuscular volume / } \\
\text { Volume corpuscular médio }\left(\mu \mathrm{m}^{3}\right)\end{array}$ & $49.75 \pm 0.77$ & $49.75 \pm 0.53$ & $46.00 \pm 0.46^{*}$ \\
\hline $\begin{array}{l}\text { Mean corpuscular hemoglobin / } \\
\text { Hemoglobina corpuscular média (pg) }\end{array}$ & $16.03 \pm 0.32$ & $16.47 \pm 0.17$ & $15.50 \pm 0.16$ \\
\hline $\begin{array}{l}\text { Mean corpuscular hemoglobin concentration / } \\
\text { Concentração média de hemoglobina corpuscular (g/dL) }\end{array}$ & $32.87 \pm 0.22$ & $33.49 \pm 0.05^{*}$ & $33.58 \pm 0.21^{*}$ \\
\hline $\begin{array}{l}\text { Red cell distribution width / } \\
\text { Amplitude de distribuição dos glóbulos vermelhos (\%) }\end{array}$ & $15.10 \pm 0.57$ & $15.40 \pm 0.56$ & $15.54 \pm 0.22$ \\
\hline Platelet / Plaquetas $\left(10^{3} / \mathrm{mm}^{3}\right)$ & $1130.0 \pm 71.2$ & $1026.1 \pm 42.4$ & $1192.0 \pm 36.5$ \\
\hline $\begin{array}{l}\text { Mean platelet volume / } \\
\text { Volume plaquetário médio }\left(\mu \mathrm{m}^{3}\right)\end{array}$ & $5.10 \pm 0.05$ & $5.12 \pm 0.07$ & $4.86 \pm 0.06^{*}$ \\
\hline White blood cells / Leucócitos $\left(10^{3} / \mathrm{mm}^{3}\right)$ & $7.40 \pm 0.24$ & $7.32 \pm 0.47$ & $12.38 \pm 0.55^{*}$ \\
\hline Neuthrophil / Neutrófilo (\%) & $4.41 \pm 0.50$ & $3.95 \pm 0.46$ & $2.24 \pm 0.21 *$ \\
\hline Eosinophil / Eosinófilo (\%) & $0.02 \pm 0.01$ & $0.03 \pm 0.01$ & $0.03 \pm 0.01$ \\
\hline Basophil / Basófilo (\%) & $0.37 \pm 0.07$ & $0.35 \pm 0.07$ & $0.34 \pm 0.04$ \\
\hline Lynfocyte / Linfócito (\%) & $94.49 \pm 0.50$ & $94.61 \pm 0.46$ & $96.69 \pm 0.37^{*}$ \\
\hline Monocyte / Monócito (\%) & $1.04 \pm 0.20$ & $0.92 \pm 0.19$ & $0.86 \pm 0.05$ \\
\hline
\end{tabular}

*Statistically different from control group, $\mathrm{p}<0.05$ (one-way ANOVA followed by Dunnett's multiple comparisons test) / *Estatisticamente diferente do grupo controle, $\mathrm{p}<0,05$ (ANOVA de uma via seguida pelo teste de comparações múltiplas de Dunnett). 


\section{Discussion}

This study aimed to assess the safety of stem bark aqueous extract of $L$. ferrea in mice administered orally for 12 weeks.

Although the animals did not present behavioral or physical changes, nor mortality, the mice showed a loss in body weight when treated with the stem bark aqueous extract of $L$. ferrea. A reduction in body weight can be indicative of the toxic action of a substance in the body $(27,28)$. However, it should be noted that the phytochemical characterization of $L$. ferrea revealed the presence of polyphenols (tannins) as a major compound (13), and this class of substance has been associated with a loss in body weight. Indeed, several studies (29, 30) show a reduction in body weight in animals and humans treated with tannins.

Joslyn and Glick (31) have also reported that the intake of tannic acid, gallic acid, or catechin induced a decrease in body weight gain in rats in a dose-dependent way and suggested that the tannins could reduce the absorption of dietary components. In our study, however, the animals present a decrease in body weight that was partially related to a decrease in food intake.

The tannin obtained from the bark of Acacia mearnsii was studied as a functional substance (32). Ikarashi et al. $(32,33)$ showed that tannins have an anti-obesity/ antidiabetic effect in obese diabetic KKAy mice. These effects were related to an increased expression of genes related to energy expenditure in skeletal muscle, decreased fatty acid synthesis, fat intake in the liver, and reduced lipase and glucosidase enzymes, which leads to a reduction in intestinal absorption of lipids and carbohydrates. However, experimental data is divergent. Lucinda et al. (22), investigating the influence of the aqueous extract of $L$. ferrea fruits $(300 \mathrm{mg} / \mathrm{kg}$, orally) on the production of sperm in rats, observed that oral administration for 52 and 104 days did not alter the animals' body weight, however with 104 days of treatment there was lower food consumption. Bachi et al. (19) demonstrated in rats that the alternating treatment for 30 days with hydroalcoholic extract of L. ferrea stem $(400 \mathrm{mg} / \mathrm{kg}$, orally) did not modify the indicators of body weight, water. and food consumption.

Tannins are reactive compounds and exert local pharmacological action in the intestine through intra-and intermolecular hydrogen bonds. High molecular weight tannins can form complexes with proteins, starches, and digestive enzymes, leading to reduced nutrient digestibility (34). In general, the pharmacokinetics

\section{Discussão}

Este estudo teve como objetivo avaliar a segurança do extrato aquoso da casca do caule de $L$. ferrea administrado por via oral em camundongos durante 12 semanas.

Os animais não apresentaram alterações comportamentais e físicas ou mortalidade, entretanto, apresentaram perda de massa corporal, quando tratados com o extrato aquoso da casca do caule de L. ferrea. A redução na massa corporal pode ser indicativa da ação tóxica de uma substância no organismo $(27,28)$. Todavia, deve-se notar que a caracterização fitoquímica de $L$. ferrea revelou a presença de polifenóis (taninos) como composto principal (13), e essa classe de substância está possivelmente associada a perda de massa corporal. De fato, alguns estudos $(29,30)$ mostram redução na massa corporal em animais e humanos tratados com taninos.

Joslyn e Glick (31) também relataram que a ingestão de ácido tânico, ácido gálico ou catequina induziu redução no ganho de massa corporal em ratos de maneira dose-dependente e sugeriram que os taninos poderiam reduzir a absorção dos componentes da dieta. Em nosso estudo, no entanto, os animais apresentaram diminuição na massa corporal que foi parcialmente relacionada a redução na ingestão de alimentos.

Ikarashi et al. (32,33) mostraram que os taninos têm um efeito anti-obesidade/antidiabético em camundongos KKAy diabéticos obesos. Esses efeitos foram relacionados ao aumento da expressão de genes relacionados ao gasto energético no músculo esquelético, diminuição da síntese de ácidos graxos, ingestão de gordura no fígado e redução das enzimas lipase e glicosidase, o que leva a redução na absorção intestinal de lipídios e carboidratos. Por outro lado, existem dados divergentes pois, Lucinda et al. (22) investigando a influência do extrato aquoso dos frutos de L. ferrea (300 mg/kg, v.o.) na produção de espermatozoides em ratos, observaram que a administração oral por 52 e 104 dias não alterou a massa corporal dos animais, mas com 104 dias de tratamento houve menor consumo de alimento. Bachi et al. (19) demonstraram em ratos que o tratamento alternado por 30 dias com extrato hidroalcóolico do caule de L. ferrea (400 mg/kg, v.o.) não modificou os indicadores massa corporal e consumos de água e alimento.

Os taninos são compostos reativos e exercem ação farmacológica local no intestino por meio de ligações de hidrogênio intra- e intermoleculares. Os taninos de alto peso molecular podem formar complexos 
of tannins are complex and their absorption in the intestine can be influenced by individual and physicalchemical characteristics, such as molecule size, degree of polymerization, solubility, and conjugation with other compounds (35). These variables may initially justify the conflicting effects observed on body weight.

The changes produced by the extract on the absolute and relative tissue weights were correlated with the histopathological findings observed. Thus, leukocyte infiltrates found in the kidneys and leukocyte intraepithelial infiltrates with areas of necrosis in the small intestine were considered relevant, indicating an inflammatory process.

Mansoori et al. (36) reported an increase in the relative weight of the intestine in chickens treated with tannic acid. Hervás et al. (37) have also observed necrosis of the intestinal villi, demarcated by an inflammatory infiltrate, in sheep after a feed with commercial quebracho tannin. The pigmented material in the intestine was associated with necrotic areas and a neutrophilic infiltrate, suggesting that it appeared after damage to the intestinal epithelium had occurred.

Biochemical data seem to support the histopathological results observed as the extract induced a decrease in total plasma proteins and albumin. This reduction may be due to enteropathies or loss of proteins due to kidney damage.

The extract also produced an increase in the values of aspartate aminotransferase, lactate dehydrogenase, and amylase. Unlike alanine aminotransferase, which is more restricted to lesions in the liver (which were not observed in this study), AST and LDH enzymes are more nonspecific and may reflect lesions in extrahepatic tissues (38).

Amylase is elevated in conditions such as pancreatitis, hepatic necrosis, cirrhosis, renal failure, and nephrectomy (38). Lesions in the small intestine that compromise the absorption of carbohydrates, even without pancreatic changes, can increase the serum level of this enzyme (39). It should be noted that tannins have an inhibitory action on alpha-amylase, which reduces blood glucose without the need for hormonal control and that contributes the antidiabetic action of these compounds $(40,41,34)$. com proteínas, amidos e enzimas digestivas levando a redução na digestibilidade dos nutrientes (34). De forma geral, a farmacocinética dos taninos é complexa e sua absorção no intestino pode ser influenciada por características individuais e físico-químicas como tamanho da molécula, grau de polimerização, solubilidade e conjugação com outros compostos (35). Essas variáveis podem justificar inicialmente os efeitos conflitantes observados sobre a massa corporal.

As alterações produzidas pelo extrato sobre a massas absolutas e relativas dos tecidos foram correlacionadas com os achados histopatológicos observados. Dessa forma, foram considerados relevantes os infiltrados leucocitários encontrados nos rins e o infiltrado intraepitelial leucocitário com áreas de necrose no intestino delgado, indicando processo inflamatório.

Mansoori et al. (36) relataram aumento na massa relativa do intestino em galinhas tratadas com ácido tânico. Hervás et al. (37) constataram necrose das vilosidades intestinais, demarcadas por infiltrado inflamatório, em ovinos, após alimentação com tanino comercial quebracho. $\mathrm{O}$ material pigmentado encontrado no intestino estava associado a áreas necróticas e a infiltrado neutrofílico, sugerindo que as alterações apareceram após a ocorrência de danos no epitélio intestinal.

Os dados bioquímicos parecem embasar os resultados histopatológicos observados já que o extrato induziu diminuição nas proteínas totais plasmáticas e albumina. Essa redução pode ser devido a enteropatias ou perda de proteínas, devido a danos renais.

O extrato também produziu elevação nos valores de aspartato aminotransferase (AST), lactato desidrogenase (LDH) e amilase. Diferente da alanina aminotransferase (ALT) que é mais restrita a lesões no fígado (que não foram observadas no estudo), as enzimas (AST e LDH) são mais inespecíficas e podem refletir lesões em tecidos extra-hepáticos (38).

A amilase encontra-se elevada em condições como pancreatite, necrose hepática, cirrose, insuficiência renal e nefrectomia (38). Lesões no intestino delgado que comprometem a absorção de carboidratos, mesmo sem alterações pancreáticas podem elevar o nível sérico dessa enzima (39). Cabe salientar, que os taninos possuem ação inibitória sobre a alfa-amilase o que reduz a glicemia sem a necessidade de controle hormonal e que contribui na ação antidiabética desses compostos $(40,41,34)$ 
The mechanism by which the plant constituents produced these lesions, requires more detailed investigations, however, it is reasonable to consider that the damage to the small intestine and kidneys likely contributed to the increase in AST, LDH, and amylase identified in the study.

During the evaluation of hematological parameters, it was observed that there were changes in the mean corpuscular volume and in the mean corpuscular hemoglobin concentration, but since the parameters of erythrocytes count, hematocrit, and hemoglobin were not affected by the treatment with $L$. ferrea, this data does not show particular clinical relevance. However, the mice treated with the extract showed an increase in the number of leukocytes and a reduction in neutrophils. Leukocytes are involved in the defense of the organism, as in inflammatory processes (42). Leukocytosis associated with neutropenia indicates that the demand for leukocytes is greater than its production. These results are consistent with those observed in histopathology and biochemistry.

As in all studies, there are limitations identified here, such as the use of crude plant extract, whose characteristic is the presence of a mixture of different chemical compounds, and thus makes it difficult to establish a cause (what/which compounds) and effect relationship. This limitation is common in studies with crude natural product extract. As a future perspective, we intend to evaluate the safety of using the extract during the gestation period and on the reproductive performance in the perception of advancing on the biological properties of $L$. ferrea.

\section{Conclusion}

In conclusion, the repeated dose-administration of the stem bark aqueous extract of the Libidibia ferrea is partially safe to the mice. The reduction in the animals' body mass suggests a possible relation to the presence of tannins in the extract. Nephro-enterotoxicity and subsequently changes in some biochemical and hematological indicators were also observed.
O mecanismo pelo qual os constituintes da planta produziram essas lesões, necessita de investigações mais detalhadas, contudo, é razoável ponderar que o agravo do intestino delgado e rins provavelmente contribuiu para o aumento da AST, LDH e amilase identificados no estudo.

Na avaliação dos parâmetros hematológicos, observouse que houve alterações no volume corpuscular médio e na concentração média de hemoglobina corpuscular, mas como os parâmetros da contagem de eritrócitos, hematócrito e hemoglobina não foram afetados pelo tratamento com L. ferrea. Esses dados foram interpretados como de baixa relevância clínica. Contudo, os camundongos tratados com o extrato apresentaram aumento no número de leucócitos e redução de neutrófilos. Os leucócitos estão envolvidos na defesa do organismo, como nos processos inflamatórios (42). A leucocitose associada a neutropenia indica que a demanda por leucócitos é superior à sua produção. Esses resultados estão coerentes com os observados na histopatologia e bioquímica.

Como todo trabalho de pesquisa, existem limitações identificadas aqui como o emprego de extrato vegetal bruto, cuja característica é a presença de uma mistura de distintos compostos químicos, e dessa forma dificulta estabelecer uma relação causa (qual/quais compostos) e efeito. Essa limitação é comum nos estudos com extrato de produtos naturais bruto. Como perspectiva futura pretende-se avaliar a segurança de uso do extrato durante o período da gestação e sobre a performance reprodutiva na percepção de avançar acerca das propriedades biológicas de L. ferrea.

\section{Conclusão}

Em conclusão, a administração de doses-repetidas do extrato aquoso da casca do caule de Libidibia ferrea é parcialmente seguro em camundongos. A redução da massa corporal dos animais sugere possível relação à presença de taninos no extrato. Também foram observados nefro-enterotoxicidade e subsequentemente alterações em alguns indicadores bioquímicos e hematológicos. 


\section{Author Contributions}

CFBV, HMLM, and JHCS performed pharmacological experiments; CRL, JCSN, and FF, carried out hematological, biochemical and histopathological analysis; SFA, and AGW designed the study, wrote, and corrected the manuscript.

\section{Acknowledgements}

The authors would like to thank Rejane de Souza for technical assistance and the National Council for Scientific and Technological Development - CNPq for financial support. Sérgio Faloni de Andrade is funded by Foundation for Science and Technology (FCT) - Scientific Employment Stimulus contract with the reference number CEEC/CBIOS/PMHD/2018.

\section{Conflict of interests}

The editor involved in the authorship of this manuscript had no participation in the review or decision process. The authors declare that there is no conflict of interest involving a personal or financial relationship associated with the publication of this manuscript.

\section{Declaração de contribuições dos autores}

CFBV, HMLM e JHCS realizaram os experimentos farmacológicos; CRL, JCSN e FF, realizaram análises hematológicas, bioquímicas e histopatológicas; SFA e AGW planejaram os experimentos, escreveram e corrigiram o manuscrito.

\section{Agradecimentos}

Os autores gostariam de agradecer a Rejane de Souza pela assistência técnica e ao Conselho Nacional de Desenvolvimento Científico e Tecnológico - CNPq pelo apoio financeiro. Sérgio Faloni de Andrade é financiado pela Fundação para a Ciência e Tecnologia (FCT) Contrato de Estímulo ao Emprego Científico com o número de referência CEEC/CBIOS/PMHD/2018.

\section{Conflito de interesses}

O editor envolvido na autoria deste manuscrito não teve qualquer participação no processo de revisão ou de decisão. Os autores declaram que não há conflito de interesses envolvendo relacionamento pessoal ou financeiro associado à publicação deste manuscrito. 


\section{References / Referências}

1. Brasil. Ministério da Saúde, Política e Programa Nacional de Plantas Medicinais e Fitoterápicos. Acesso disponível em agosto de 2020: https://www.saude.gov.br/acoes-e-programas/programa-nacional-de-plantas-medicinais-e-fitoterapicos-ppnpmf/politica-e-programanacional-de-plantas-medicinais-e-fitoterapicos.

2. Brasil. Formulário de fitoterápicos da farmacopeia brasileira/Agencia Nacional de Vigilância Sanitária (ANVISA). Brasília, 2011.

3. The International Plant Names Index, 2009. In: URL: http://www.ipni.org/

4. Bacchi EM, Sertié JAA, 1994. Antiulcer action of Styrax camporum and Caesalpinia ferrea in rats. Planta Med 1994; 60:118-20.

5. Prazeres LDKT, Aragão TP, Brito SA, Almeida, CLF, Silva AD, Paula MMF, Farias JS, Vieira LD, Damasceno BPGL, Rolim LA, Veras BO, Rocha IG, Silva-Neto JC, Bittencourt MLF, Gonçalves RCR, Kitagawa RR, Wanderley AG. Antioxidant and antiulcerogenic activity of the dry extract of pods of Libidibia ferrea Mart. ex Tul. (Fabaceae). Oxid Med Cell Longev 2019; 2019:1983137.

6. Carvalho JCT, Teixeira JRM, Souza PJC, Bastos JK, Santos Filho D, Sarti SJ. Preliminary studies of analgesic and anti-inflammatory properties of Caesalpinia ferrea crude extract. J. Ethnopharmacol 1996;53:175-78.

7. Freitas ACC, Lins TUL, Ximenes NCA, Magalhães LR, Gonçalves-Silva T, Aguiar JS, Coelho LCBB, Correia MTS, Nascimento SC, Carneiro-da-Cunha MG. Biological activities of Libidibia (Caesalpinia) ferrea var. parvifolia (Mart. ex Tul.) L. P. Queiroz pod preparations. J Evid Based Complementary Altern Med 2012;2012:ID 514134.

8. Falcão TR, Rodrigues CAO, de Araújo AA, et al. Crude extract from Libidibia ferrea (Mart. ex. Tul.) L.P. Queiroz leaves decreased intra articular inflammation induced by zymosan in rats. BMC Complement Altern Med 2019;19(1):47.

9. Gonzalez FG, Barros SBM, Bachi EM. Atividade antioxidante e perfil fitoquímico de Caesalpinia ferrea Mart. Braz J Pharmac Sci 2004;40:78.

10. Nozaki H, Hayashi K, Kido M, Kakumoto K, Ikeda S, Matsuura N, Tani H, Takaoka D, Linumae M, Akaof Y. Pauferrol A, a novel chalcone trimer with a cyclobutane ring from Caesalpinia ferrea Mart exhibiting DNA topoisomerase II inhibition and apoptosis-inducing activity. Tetrahedron Lett 2007;48:8290-92.

11. Calandrini de Azevedo LF, Alves Ferreira TA, Melo KM, et al. Aqueous ethanol extract of Libidibia ferrea (Mart. Ex Tul) L.P. Queiroz (juca) exhibits antioxidant and migration-inhibiting activity in human gastric adenocarcinoma (ACP02) cells. PLoS One. 2020;15(1):e0226979.

12. Menezes IAC, Moeira IJA, Carvalho AA, Antoniolli AR, Santos MRV. 2007.Cardiovascular effects of the aqueous extract from Caesalpinia ferrea: Involvement of ATP-sensitive potassium channels. Vascul Pharmacol 2007;47:41-7.

13. Vasconcelos CFB, Maranhão H M L, Batista TM, Carneiro EM, Ferreira F, Costa J, Soares LAL, Sá MDC, Souza TP, Wanderley AG. Hypoglycaemic activity and molecular mechanisms of Caesalpinia Ferrea Martius bark extract on streptozotocin-induced diabetes in Wistar rats. J Ethnopharmacol 2011; 137:1533-41.

14. Guerra ACVA, Soares LAL, Ferreira MRA, Araújo AA, Rocha HAO, Medeiros JS, Cavalcante RDS, Júnior RFA. Libidibia ferrea presents antiproliferative, apoptotic and antioxidant effects in a colorectal cancer cell line. Biomed Pharmacother 2017; 92:696-706..

15. Zanin JLB, De Carvalho BA, Martineli SP, Dos Santos MH, Lago JHG, Sartorelli P, Viegas CJr, Soares MG. The genus Caesalpinia L. (Caesalpiniaceae): Phytochemical and pharmacological characteristics. Molecules 2012;17:7887-902.

16. Ferreira DQ, Ferraz TO, Araújo RS, et al. Libidibia ferrea (jucá), a Traditional anti-inflammatory: A study of acute toxicity in adult and embryos zebrafish (Danio rerio). Pharmaceuticals (Basel). 2019;12(4):175-90.

17. Costa, LMT, Guilhon-Simplicio F, Souza, TP. Libidibia ferrea (Mart. Ex tul) L. P. Queiroz var. Ferrea: Pharmacological, phytochemical and botanical aspects. Int J Pharm Pharm Sci 2015;7(4):48-53.

18. Ferreira MRA, Soares LAL. Libidibia ferrea (Mart. Ex tul) L. P. Queiroz; A review of the biological activities and phytochemical composition. JMPR. 2015;9(2):140-50.

19. Bacchi E, Sertié J, Villa N, Katz H. Antiulcer action and toxicity of Styrax camporum and Caesalpinia ferrea. Planta Med. 1995;61(03):204-07.

20. Peters VM, Souza OS, Carvalho JCT, Borges LV, Guerra MO. Evaluation of reproductive toxicity of aqueous extract of the fruits from Caesalpinia ferrea Mart. in rats. Bol Latinoam Caribe Plant Med Aromat 2008;7:268-72.

21. Pickler TB, Lopes KP, Magalhães SA, Krueger CMA, Martins MM, Filho VC, Jozala AF, Grotto D, Gerenutti M. Effect of Libidibia ferrea bark and seed in maternal reproductive and biochemical outcomes and fetal anomaly in rats. Birth Defects Res. 2019;111(13):863871.

22. Lucinda LMF, Rocha CB, Reboredo MM, Faria VC, Sá, RCS. Assessment of sperm production and reproductive organs of Wistar rats to long-term exposure of Caesalpinia ferrea. An Acad Bras Cienc. 2010;82(4):907-914.

23. Washington, DC. Guide for the care and use of laboratory animals, 8th edition, 2011.

24. Malone RA. Pharmacological approaches to natural products screening and evaluation. In: Warner, H., Wolf, P. (Eds.), New natural products and plant drugs with pharmacological, biological or therapeutical activity. Springer-Verlag, Berlin, 24-53, 1977.

25. Caldas GF, Limeira MM, Araújo AV, Albuquerque GS, Silva-Neto JC, da Silva, TG, Costa-Silva JH, de Menezes IRA, da Costa JGM, Wanderley AG. Repeated-doses and reproductive toxicity studies of the monoterpene 1,8-cineole (eucalyptol) in Wistar rats. Food Chem Toxicol 2016;97:297-306.

26. Lison L. Histochimie et cyytochimie animals. Paris Gauthiers - Villars, 842, 1960.

27. Jahn AI and Gunzel PKH. The value of spermatology in male reproductive toxicology: do spermatologic examinations in fertility studies provide new and additional information relevant for safety assessment? Reprod Toxicol 1997; 11: 171-78.

28. Chapman K, Sewell F, Allais L, Delongeas J-L, Donald E, Festag M, Kervyn S, Ockert D, Nogues V, Palmer H, Popovic M, Roosen W, Schoenmakers A, Somers K, Stark C, Stei P, Robinson S. A global pharmaceutical company initiative: an evidence-based approach to define the upper limit of body weight loss in short term toxicity studies. Regul Toxicol Pharmacol 2013;67:27-38.

29. Ekambaram SP, Babu KB, Perumal SS, Rajendran D. Repeated oral dose toxicity study on hydrolysable tannin rich fraction isolated from fruit pericarps of Terminalia chebula Retz in Wistar albino rats. Regul Toxicol Pharmacol 2018;92:182-88. 
30. Gheflati MM, Nahid R-J, Zahra H, Amin S-A, Azadeh N. Does pomegranate consumption affect weight and body composition? A systematic review and meta-analysis of randomized controlled clinical trials Alireza. Phytother Res 2019;1-12.

31. Joslyn MA, Glick Z. 1969. Comparative effects of gallotannic acid and related phenolics on the growth of rats. J. Nutr. 1969;98,119-26.

32. Ikarashi N, Toda T, Okaniwa T, Ito K, Ochiai W, Sugiyama K. Anti-obesity and anti-diabetic effects of Acacia polyphenol in obese diabetic KKAy mice fed high-fat diet. Evid-Based Complement Alternat Med 2011;2011:952031.

33. Ikarashi N, Takeda R, Ito K, Ochiai W, Sugiyama K. The inhibition of lipase and glucosidase activities by Acacia polyphenol. EvidBased Complement Alternat Med 2011;2011:272075.

34. Smeriglio A, Barreca D, Bellocco E, Trombetta D. Proanthocyanidins and hydrolysable tannins: occurrence, dietary intake and pharmacological effects. Br J Pharmacol. 2017;174(11):1244-262.

35. Silva CP, Sampaio GR, Freitas RAMS, Torres EAFS. Polyphenols from guaraná after in vitro digestion: Evaluation of bioacessibility and inhibition of activity of carbohydrate-hydrolyzing enzymes. Food Chem. 2018;267:405-409.

36. Mansoori B, Nodeh H, Modirsanei M, Kiaei MM, Farkhoy M. Influence of dietary tannic acid and polyethylene glycol on growth and intestinal D-xylose absorption of broiler cockerels and activity of serum enzymes. Br Poult Sci 2007;48:489-95.

37. Hervás G, Pérez V, Giráldez FJ, Mantecón AR, Almar MM, Frutos P. Intoxication of sheep with quebracho tannin extract. J. Comp. Pathol. 2003;129:44-54.

38. Arika WM, Nyamai DW, Osano KO, Ngugi MP, Njagi ENM. Biochemical Markers of In Vivo Hepatotoxicity. J. Clin. Toxicol. 2016;6:1000297-305.

39. Dreiling DA, Janowitz HD, Marshall D, Haemmerli P. Relationship between blood amylase and factors affecting carbohydrate metabolism. Am J Dig Dis 1959;3:214-19.

40. Bueno, P.S.A., Kato-Schwartz, C.G., de Souza Lima, D. et al. In silico evaluation of condensed and hydrolysable tannins as inhibitors of pancreatic $\alpha$-amylase. J Mol Model 2019;25:275.

41. Alam F, Shafique Z, Amjad ST, Bin Asad MHH. Enzymes inhibitors from natural sources with antidiabetic activity: A review. Phytother Res 2019;33(1):41-54.

42. Wang J. Neutrophils in tissue injury and repair. Cell Tissue Res 2018; 371:531-39. 